\title{
Hereditary ectodermal dysplasia, olivopontocerebellar degeneration, short stature, and hypogonadism*
}

\author{
ALAN R RUSHTON†AND MYRON GENEL \\ From the Department of Pediatrics, Yale University School of Medicine, and \\ Yale-New Haven Hospital, New Haven, Connecticut, USA
}

SUMMARY Two teenaged children born of normal parents in a consanguineous family had evidence of abnormal neurological, endocrine, and ectodermal development. They had mental retardation, hearing loss, ocular dysmetria, hyperreflexia, and ataxia consistent with olivopontocerebellar degeneration. They had hypogonadotrophic hypogonadism and extremely short stature despite normal serum growth hormone and somatomedin-C. There was also hypodontia with peg shaped teeth and mid-face hypoplasia. This syndrome of hypoplasia of mid-line structures appeared to be inherited as an autosomal recessive trait.

Ectodermal dysplasia is a general term for hereditary disorders which are characterised by abnormal skin, hair, nails, or teeth. A recent review has delineated approximately 55 different syndromes with anomalous development of ectodermal elements. ${ }^{1}$ Olivopontocerebellar degeneration is one of the hereditary spinocerebellar degeneration syndromes with ataxia and tremor, as well as various other motor and sensory deficits. ${ }^{2} 3$

We have had the opportunity to investigate two children from a consanguineous family who have a unique syndrome characterised by abnormal ectodermal and neurological development as well as short stature and absence of sexual maturation.

\section{Case reports}

The index case was the $3488 \mathrm{~g}$ product of an uncomplicated term pregnancy and was delivered by caesarean section for cephalopelvic disproportion. Developmental milestones appeared normal to the parents, but he was referred to a children's hospital at the age of 3 years for failure to thrive. Physical examination revealed a proportionately small child. Laboratory evaluation showed normal serum calcium, phosphate, and protein bound iodine, and

\footnotetext{
*Patients were studied in the Children's Clinical Research Center, supported by Grant RR-125 from the General Clinical Research Center's Program, Division of Research Resources, National Institutes of Health.

†Present address: Department of Pediatrics, Hunterdon Medical Center, Flemington, New Jersey 08822, USA.

Received for publication 16 September 1980
}

normal urine amino-acids. Skull $x$-rays and wrist bone age were also normal.

Mental retardation became evident after he entered primary school. Testing revealed an IQ of 51 . He continued to grow very slowly and was reevaluated at 10 years of age. His weight and height were far below the 3 rd centile while his head circumference was normal. Physical examination revealed prognathism and hyperreflexia in the lower extremities. Wrist bone age was $8 \frac{1}{2}$ years. Arginine stimulated growth hormone testing was normal.

Another evaluation at 163 years again showed height and weight below the 3 rd centile. Serum thyroxine, cholestrol, alkaline phosphatase, calcium, and phosphate were all normal. Serum testosterone, prolactin, FSH, and LH were in the prepubertal range. Growth hormone levels after levodopa stimulation were normal.

The patient was referred to the Yale Pediatric Endocrinology Service for evaluation of growth when he was 18 years old. Family history revealed that the parents were first cousins from a small village in Italy. The proband (IV.5) and his younger sister (IV - 7) were both very short, while a brother (IV-6) appeared to be of normal height (fig 1).

Physical examination of the proband revealed weight $37 \mathrm{~kg}$, height $133 \mathrm{~cm}$, and head circumference $53 \mathrm{~cm}$. He was alert but mentally dull. The skull was normocephalic with relative mid-face hypoplasia, giving the impression of prognathism. The hair was straight and dark brown (fig 2). Ophthalmological examination was normal. Dental 


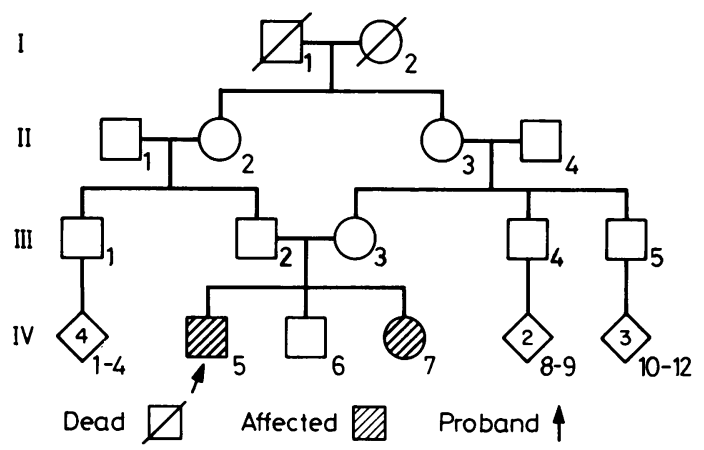

FIG 1 Family pedigree showing affected patients and their first cousin parents. examination showed anterior open bite with Angle class III occlusion. The permanent teeth were incomplete with congenitally absent premolars. The remaining teeth were widely spaced and peg shaped with enamel hypoplasia (fig 3 ). Audiometry revealed a $60 \mathrm{db}$ hearing loss above $2000 \mathrm{~Hz}$ in the left ear. The skin, nails, and sweat glands were normal. Neurological examination showed normal optic fundi and discs. There was no nystagmus but he showed ocular dysmetria and saccadic pursuit movements. The other cranial nerves were intact. Examination of the motor system demonstrated no muscle weakness or wasting and tone was normal. Co-ordination testing showed slowing of rapid alternating movements and bilateral intention tremor in the limbs with truncal titubation. The

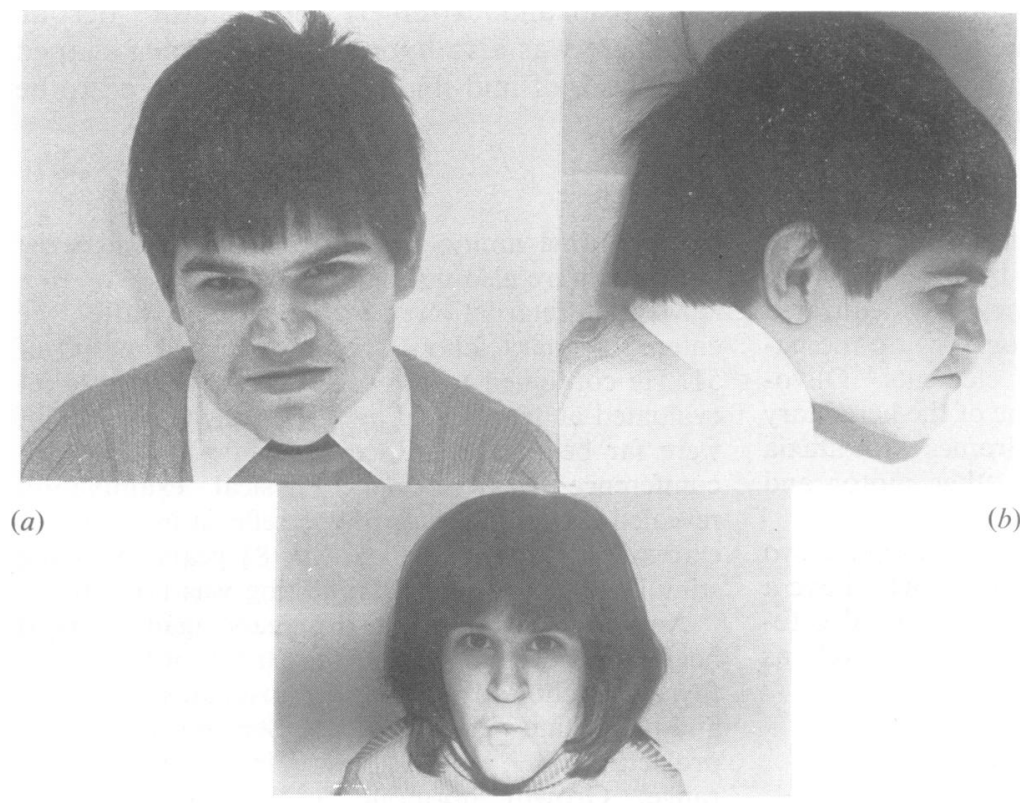

FIG 2 (a) Frontal and (b) lateral face views of the proband IV.5, (c) frontal face view of his sister IV $\cdot 7$.

(c)

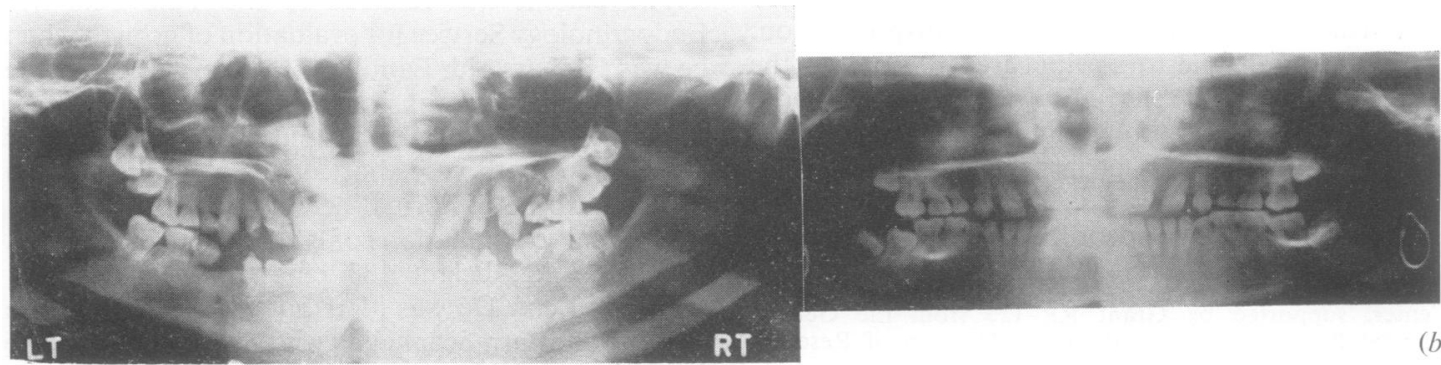

(a)

FIG 3 Panorex dental radiographs of (a) the proband IV.5 and (b) his sister IV.7, showing hypodontia (absent premolars) and widely spaced, peg shaped teeth. 
gait was broad based and very ataxic. Sensation for pain, joint position, and vibration was intact. The tendon reflexes were increased in both upper and lower limbs and the left plantar response was extensor. The spine and feet were normal. The patient could speak and follow simple commands in the concrete manner of a small child. Sexual development was Tanner stage II. ${ }^{4}$

The brother (IV-6) was 17 years old, had a height of $164 \mathrm{~cm}$, weight $57 \mathrm{~kg}$, and head circumference $54 \mathrm{~cm}$. Physical examination of this child and the parents (III·2 and 3 ) was normal.

The sister (IV-7) was 14 5/12 years old. Developmental history was similar to that of her affected brother. Her height was $137 \mathrm{~cm}$, weight $35.5 \mathrm{~kg}$, and head circumference $52 \mathrm{~cm}$. Dentition and facies were the same as her older brother. Neurological examination was also identical except that she lacked the Babinski sign. Audiometry was normal. Sexual development was Tanner stage I.

\section{LABORATORY RESULTS}

The following tests were within normal limits for both affected sibs: serum cholesterol, $\beta$-lipoproteins, glucose, urea nitrogen, creatinine, electrolytes, calcium, phosphate, total protein and albumin, and alkaline phosphatase.

Endocrine evaluation showed normal serum prolactin, cortisol, and thyroxine as well as appropriate growth hormone response to levodopa stimulation. Other results are presented in the table.

Radiological examination showed normal skull, hands, and feet. The proband had a wrist bone age of $13 \frac{1}{2}$ years, while his sister scored 11 years. Computed tomography of both children revealed cerebellar atrophy (fig 4).

\section{Discussion}

Two children born of normal parents in a consanguineous family demonstrated retardation of normal somatic growth and sexual maturation.

\section{TABLE Laboratory results}

\begin{tabular}{lll}
\hline Test & \multicolumn{1}{l}{ Patient } & \\
\cline { 2 - 3 } & Male IV.5 & Female IV.7 \\
\hline FSH $(\mathrm{U} / \mathrm{ml})$ & 2,3 & 2 \\
LH (U/ml) & 7,4 & 3 \\
Testosterone (ng/ml) & $0 \cdot 42,0 \cdot 12,0 \cdot 28$ & $0 \cdot 21$ \\
Oestrogen E2 (pg/ml) & $2 \cdot 2,2 \cdot 0$ & $\leq 20$ \\
Somatomedin-C (U/ml)* & $46, \mathrm{XY}$ & $2 \cdot 0$ \\
Karyotype (Giemsa banding) & $46, \mathrm{XX}$ \\
\hline
\end{tabular}

* Radioimmunoassay performed by Nichols Institute, San Pedro, California, USA by the method of Furlanetto et al. 5

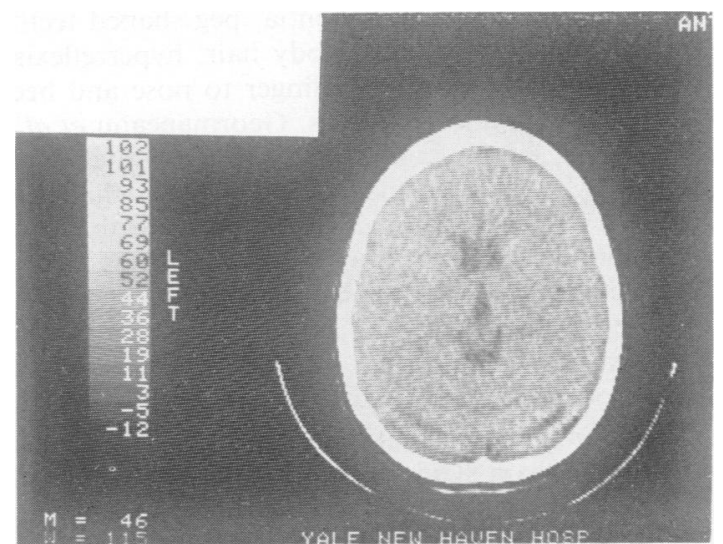

FIG 4 Computed tomogram of the brain of patient IV.7 showing bilateral cerebellar hemispheric atrophy.

They had mid-face hypoplasia with hypodontia and peg shaped teeth with enamel defects. Neurological examination showed mild mental retardation, hearing loss, ocular dysmetria with saccadic pursuit movements, hyperreflexia, marked truncal and limb ataxia, and a broad-based gait.

The children had normal stimulated growth hormone, and their somatomedin-C levels were at the upper limit of normal for their chronological or bone ages. ${ }^{5} 6$ Their lack of normal growth implies tissue unresponsiveness to growth hormone and somatomedin. The absence of sexual maturation with low serum FSH and LH is consistent with hypogonadotrophic hypogonadism ${ }^{7}$ or with severe developmental delay as reflected by their markedly retarded bone ages. Mid-face hypoplasia with absent or malformed teeth has been reported as a feature of several of the ectodermal dysplasia syndromes. ${ }^{8}$

The constellation of neurological symptoms places these children among the hereditary spinocerebellar degeneration syndromes. Their clinical signs are most consistent with olivopontocerebellar degeneration. ${ }^{2}$ Atrophy of the cerebellum, as demonstrated by computed tomography in these children, was similar to that described previously in other cases by Gilroy and Lynn. ${ }^{9}$

The association of ectodermal dysplasia and spinocerebellar degeneration has been reported in two previous families. Klingmüller and Kirchhof ${ }^{10}$ described four male children born of a father stated to have Friedreich's ataxia and a mother who was clinically normal but had a brother with an unspecified 'general movement disorder'. The children had normal growth and mental development with 
mid-face hypoplasia, hypodontia, peg shaped teeth, hypotrichosis, thin scanty body hair, hyperreflexia, intention tremor, abnormal finger to nose and heel to shin testing, and pes cavus. Geormaneanu et al ${ }^{11}$ described a single female child born of unaffected parents who had normal stature and intelligence, mid-face hypoplasia, widely spaced teeth, thin curly monilethric hair, horizontal nystagmus, broad based gait, spinal lordosis and pes cavus, abnormal finger to nose testing and an intention tremor. All these cases are consistent with a cerebellar ataxia and ectodermal dysplasia.

The familial aggregation of hypogonadism and cerebellar ataxia syndromes has also been reported. Richards and Rundle ${ }^{12}$ described five affected children (two males and three females), born of normal parents in a consanguineous family, who had normal height, absent sexual development, deafness, and neurological symptoms compatible with a cerebellar ataxia. Necropsy examination of several of these patients revealed spino-olivo-dentate degeneration with involvement of the vestibularcochlear nuclei. ${ }^{13}$ Another family had two affected sibs (one male and one female), born of normal parents, who were tall and thin, and lacked maturation of secondary sexual characteristics. They were mentally retarded, and their neurological syndrome of truncal and extremity ataxia was most compatible with olivopontocerebellar degeneration. ${ }^{14}$ Matthews and Rundle ${ }^{15}$ reported two eunuchoid brothers with mental retardation, bilateral sensorineural deafness, and cerebellar ataxia. There was no consanguinity. Urinary gonadotrophins from the affected brothers were in the prepubertal range. Two more male patients with hypogonadism and neurological symptoms compatible with a cerebellar ataxia were described in a family by Volpe et al. ${ }^{16}$ Their karyotypes were $46, \mathrm{XY}$, and urinary gonadotrophins were less than $6 \mathrm{U} / \mathrm{ml}$. Four affected children (two males and two females) were born of second cousin parents in a family described by Neuhäuser and Opitz. ${ }^{17}$ The patients had normal height and weight, absent sexual development with low serum gonadotrophins, and a cerebellar ataxia.

The ectodermal dysplasias are a heterogeneous group of syndromes inherited as autosomal dominant, recessive, or $\mathrm{X}$ linked traits. ${ }^{8}$ Olivopontocerebellar degeneration may be inherited in an autosomal dominant or recessive manner, ${ }^{2}$ while Friedreich's ataxia is an autosomal recessive disorder. ${ }^{18}$ Hypogonadotrophic hypogonadism can be inherited as an autosomal recessive or dominant trait. ${ }^{19-21}$ One form of hypogonadotrophic hypogonadism, Kallmann's syndrome, is associated with defects in olfaction and hypoplasia of midline structures. ${ }^{21}$
Short stature resulting from end organ unresponsiveness to normal stimulation by growth hormone and somatomedin is a racial trait characteristic of the African pygmy. Progeny of Bantu and pygmy matings are intermediate in stature between the parents. The precise mode of inheritance, however, remains unknown. ${ }^{202}$

The previously reported families have documented the association of two rare genetic traits: one of the spinocerebellar degeneration syndromes plus ectodermal dysplasia or hypogonadotrophic hypogonadism. The fact that certain subjects within these consanguineous families exhibited only one trait implied that two closely linked genes were segregating rather than one gene which resulted in both phenotypes as a result of pleiotropic effects. ${ }^{23}$ The two children from the consanguineous family presented in this report appeared to have inherited four distinct hereditary traits in an autosomal recessive manner. Their symptoms of ectodermal dysplasia, olivopontocerebellar degeneration, hypogonadotrophic hypogonadism, and short stature because of end organ unresponsiveness could be the result of a defect in a single gene necessary for the normal development of a great number of different systems. A second explanation would be the chance association of two or more linked recessive genes whose expression in the homozygote produced abnormal ectodermal, neurological, and endocrinological consequences. The results of this investigation indicate once again that symptoms of one genetic syndrome cannot be viewed in isolation. Each individual patient must be evaluated in entirety so that a precise diagnosis can be made for accurate genetic counselling and family planning.

The authors wish to thank Dr Nathan Lassman of Hartford, Connecticut for referral of the patients and continued interest in their evaluation. Neurological examination was performed by Dr L Ment, and dental assessment was provided by D W Kohn, DDS. The nursing staff of the Children's Clinical Research Center provided invaluable assistance during the endocrinological evaluation of these children.

\section{References}

1 Freire-Maia N. Ectodermal dysplasia revisited. Acta Genet Med Gemellol 1977;26:121-31.

2 Konigsmark BW, Weiner LP. The olivopontocerebellar atrophies: a review. Medicine 1970;49:227-41.

3 Bobowich AR, Brody JA. Epidemiology of neurodegenerative system disorders. In: Vinken PJ, Bruyn GW, eds. Handbook of clinical neurology. Amsterdam: North Holland, 1975: 16-9. 
4 Tanner JM. Growth at adolescence. Oxford: Blackwell, 1962.

5 Furlanetto RW, Underwood LE, Van Wyk JJ, D'Ercole AJ. Estimation of somatomedin-C levels in normals and patients with pituitary disease by radioimmunoassay. J Clin Invest 1977;60:648-57.

6 Phillips LS, Vassilopoulou-Sellin R. Somatomedins. $N$ Engl J Med 1980;302:438-46.

7 Roth JC, Kelch RP, Kaplan SL, Grumbach MM. FSH and $L H$ response to luteinizing hormone releasing factor in prepubertal children, adult males and patients with hypogonadotrophic and hypergonadotrophic hypogonadism. J Clin Endocrinol Metab 1972;35:926-30.

${ }^{8}$ Sedano HO, Sauk JJ, Gorlin RJ. Oral manifestations of inherited disorders. Boston: Butterworths, 1977:162-5.

9 Gilroy J, Lynn GE. Computerized tomography and auditory-evoked potentials. Use in the diagnosis of olivopontocerebellar degeneration. Arch Neurol 1978; $35: 143-7$.

10 Klingmüller G, Kirchhof JKJ. Über die erbliche ektodermale Dysplasie mit Anhidrosis und cerebellar Heredoataxie im Sinne einer Friedreichschen Erkrankung. Hautarzt 1954;5:351-7.

11 Geormaneanu M, Walter A, Lazarescu P. Spinocerebellare Ataxie assoziiert mit Monilethrix, eigenartigen Gesichtszüger und Zahnonomalie. Monatsschr Kinderheilkd 1976;124:647-9.

12 Richards BW, Rundle AT. A familial hormonal disorder associated with mental deficiency, deaf mutism and ataxia.J Ment Defic Res 1959;3:33-55.

13 Sylvester PS. Spino-cerebellar degeneration, hormonal disorder, hypogonadism, deaf mutism and mental deficiency. J Ment Defic Res 1972;16:203-14.
14 Altschul R, Kotlowski K. Pallido-cerebello-olivary degeneration with eunuchoidism. J Nerv Ment Dis 1956; 123:112-6.

15 Matthews WB, Rundle AT. Familial cerebellar ataxia with hypogonadism. Brain 1964;87:463-8.

16 Volpe R, Metzler WS, Johnston MW. Familial hypogonadotrophic eunuchoidism with cerebellar ataxia. $J$ Clin Endocrinol Metab 1963;23:107-15.

17 Neuhäuser G, Opitz JM. Autosomal recessive syndrome of cerebellar ataxia and hypogonadotrophic hypogonadism. Clin Genet 1975;7:426-34.

18 Greenfield JG. The Spino-cerebellar degenerations. Oxford: Blackwell, 1954.

19 Le Marquand HS. Congenital hypogonadotrophic hypogonadism in five members of a family, three brothers and two sisters. Proc R Soc Med 1954;47:442-6.

20 Rimoin DL, Schimke RN. Genetic disorders of the endocrine glands. St Louis: Mosby, 1971.

21 Santen RJ, Paulsen CA. Hypogonadotrophic eunuchoidism. I. Clinical study of the mode of inheritance. J Clin Endocrinol Metab 1973;36:47-54.

22 Rimoin DL, Merimee TJ, Rabinowitz D, Cavalli-Sforza LL, McKusick VA. Peripheral subresponsiveness to human growth hormone in the African pygmies. $N$ Engl J Med 1969;281:1383-8.

23 Skre H, Bassöe HH, Berg K, Frövig AG. Cerebellar ataxia and hypergonadotrophic hypogonadism in two kindreds. Clin Genet 1976;9:234-44.

Requests for reprints to Dr A R Rushton, Department of Pediatrics, Hunterdon Medical Center, Flemington, New Jersey 08822, USA. 